\title{
THE DYNAMIC AND METADYNAMIC RECRYSTALLISATION OF IN 718
}

\author{
Robert P. Guest ${ }^{1}$, Sammy Tin $^{2}$ \\ ${ }^{1}$ Firth Rixson Ltd, Firth House, P. O. Box 644, Meadowhall Road. Sheffield. S9 1JD \\ ${ }^{2}$ Department of Materials Science and Metallurgy, New Museum Site, \\ Cambridge University, Pembroke Street, Cambridge. CB2 3QZ
}

Keywords: Hot deformation, Recrystallisation, Microstructural evolution

\begin{abstract}
The recrystallisation behaviour of IN 718 has been analysed using a Gleeble 1500 thermomechanical simulator. The use of a rapid water quenching system immediately after the compression test has resulted in the ability to separate dynamic behaviour from meta-dynamic. The rate of dynamic recrystallisation has been found to be proportional to temperature and strain, but inversely proportional to strain rate. The nucleation rate of recrystallised grains during deformation has been found to be directly linked to strain rate and temperature. The rate of meta-dynamic recrystallisation appears to be directly proportional to temperature and strain rate, but no new nucleation events were observed after the end of deformation
\end{abstract}

\section{Methods}

Material was supplied for the experiments by Firth Rixson Forgings Ltd in the form of a forged and rolled billet of IN 718. Cylindrical samples of height $12 \mathrm{~mm}$ and diameter $8 \mathrm{~mm}$ were spark eroded from the billet and deformed using a Gleeble 1500 thermomechanical simulator.

Initially, the effects of temperature and strain rate on dynamic recrystallisation were investigated. Samples were deformed at a temperature of either $980^{\circ} \mathrm{C}$ or $1040^{\circ} \mathrm{C}$ to predefined strains of $0.09,0 \cdot 18,0 \cdot 29,0.41,0.53,0.67$, and 0.82 at a set die velocity resulting in average strain rates of $0 \cdot 01,0 \cdot 1,0 \cdot 45$, and $1 \cdot 1 \mathrm{~s}^{-1}$ followed by an immediate water quench. To investigate meta-dynamic recrystallisation, samples deformed to a strain of 0.82 were also held at the test temperature for times ranging from 1 second to 10 minutes before undergoing a water quench. Each experiment begins with a linear heat-up to test temperature over 2 minutes and then a hold for 1 minute. The tests were followed by a water quench designed to reduce the temperature of the sample as quickly as possible. Figure 1 shows the temperature profile of a typical test, showing the heat-up, hold, and quench. Thermal data is plotted for both the centre of the sample, and either end, measured using thermocouples welded to the sample. It can be seen that, although a large thermal gradient exists during the heating stage, after a 1 minute hold period, the sample is at a uniform temperature. Referring to Figure 1 (b), it can be seen that the water quench stage lowers the temperature of the specimen extremely rapidly. It takes only 1.1 seconds for the sample to reach $200^{\circ} \mathrm{C}$, and less than $0 \cdot 2$ seconds for the centre of the sample to fall below $800^{\circ} \mathrm{C}$ (a temperature below which the rate of recrystallisation is almost zero). 


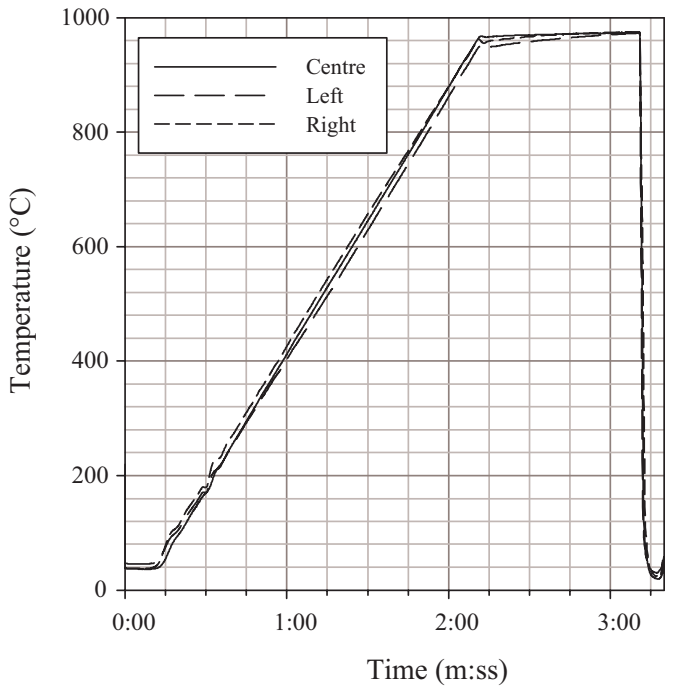

(a) Full experimental run

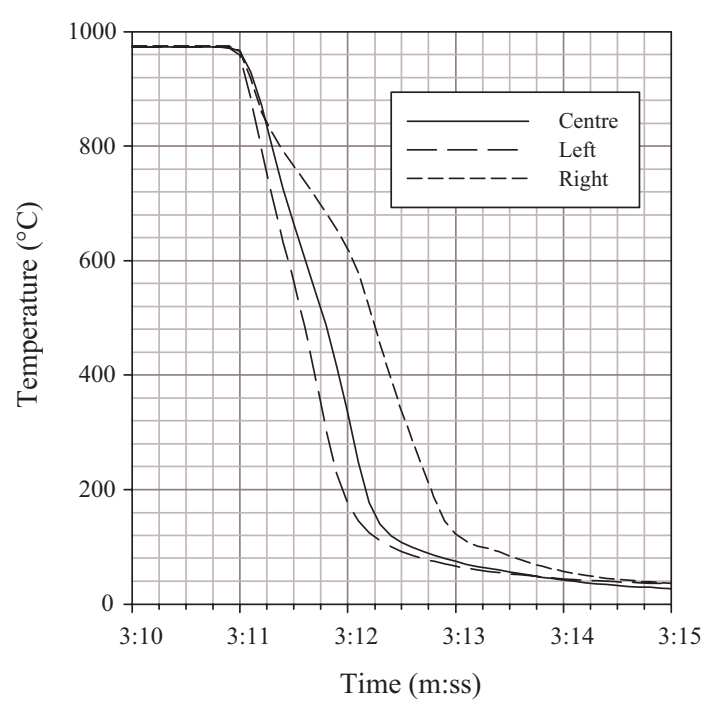

(b) Quench

Figure 1: Thermal histories for samples tested using the Gleeble 1500 showing the temperature at the centre and either end of the specimen

Following the completion of the test, the samples were sectioned along the compression axis and polished and etched using standard metallurgical techniques. Optical micrographs were than taken and the volume fraction recrystallised and grain density determined.

The starting billet microstructure is shown in Figure 2, where it can be seen that the grains are roughly equiaxed having an average diameter of approximately $20 \mu \mathrm{m}$, with numerous carbides situated on the grain boundaries.

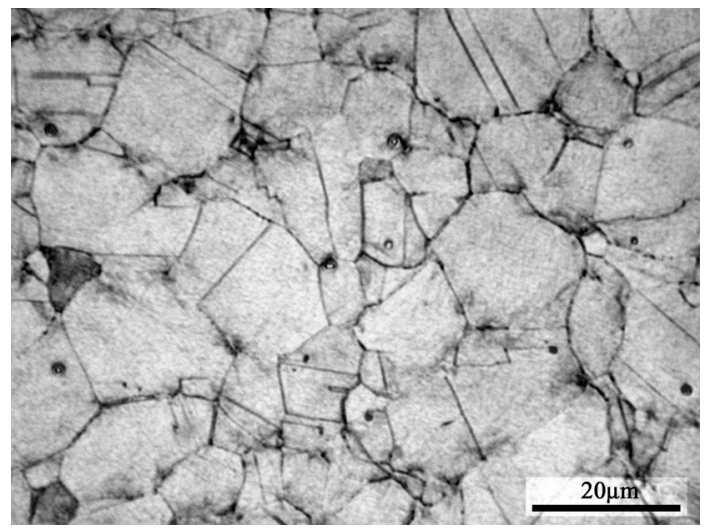

Figure 2: Optical micrograph showing the microstructure of the initial billet

\section{Results and Discussion}

Figure 3 shows the volume fraction recrystallised at $980^{\circ} \mathrm{C}$ during and after deformation. The left-hand portion of the graph clearly shows the strain rate dependent nature of dynamic recrystallisation, with a lower strain rate resulting in a higher volume fraction recrystallised. At $980^{\circ} \mathrm{C}$, compression to a strain of 0.82 results in over $60 \%$ dynamic recrystallisation at a strain rate of $0.01 \mathrm{~s}^{-1}$, whereas less than $10 \%$ dynamic recrystallisation occurs when the strain rate is increased to $1 \cdot 1 \mathrm{~s}^{-1}$. The dynamic recrystallisation curves for the two lowest strain rates show sigmoidal behaviour, with the rate of recrystallisation decreasing after a 


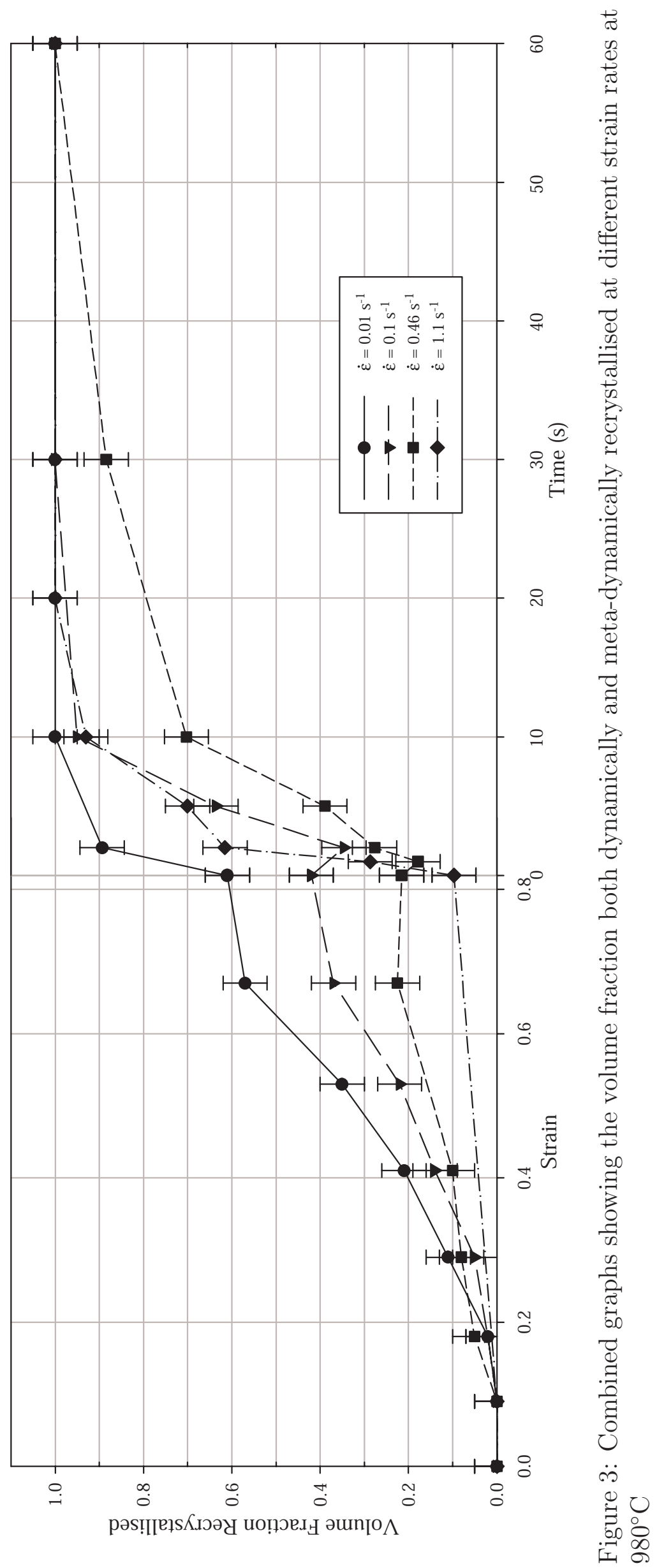


strain of approximately $0 \cdot 6$. The critical strain for the onset of dynamic recrystallisation at this temperature can be seen to be between 0.1 and 0.2 for all strain rates. The curves to the right-hand side of the graph show the meta-dynamic recrystallisation behaviour at $980^{\circ} \mathrm{C}$. Although the graph seems to show an increase in the rate of recrystallisation, it is important to note that the two $\mathrm{x}$-axis scales (strain and time) can not be compared in this fashion as the deformation time varies widely depending on the strain rate. A graph showing the volume fraction recrystallised at $980^{\circ} \mathrm{C}$ with reference to time only is shown in Figure 4 . The meta-dynamic recrystallisation rate for the samples deformed at a strain rate of $1.1 \mathrm{~s}^{-1}$ is greater than that of the other strain rates. There are two possible reasons for this. Firstly, as has already been shown, adiabatic heating during deformation raises the temperature of the samples. Finite element analysis of the test procedure has shown that at the highest strain rates, the temperature at the centre of the sample is increased by almost $50^{\circ} \mathrm{C}$. This results in the first few seconds of meta-dynamic recrystallisation occurring in a hotter environment than the specified test temperature. Secondly, the short time period over which deformation is occurring during the high strain rate test will decrease the amount of recovery allowed to occur, thus providing a higher dislocation density difference between the recrystallised grains and the original matrix and, therefore, a higher driving force for the growth of the recrystallising grains. Other than the test carried out at a strain rate of $0.46 \mathrm{~s}^{-1}$, full recrystallisation occurred within 30 seconds after deformation for all experiments at $980^{\circ} \mathrm{C}$.

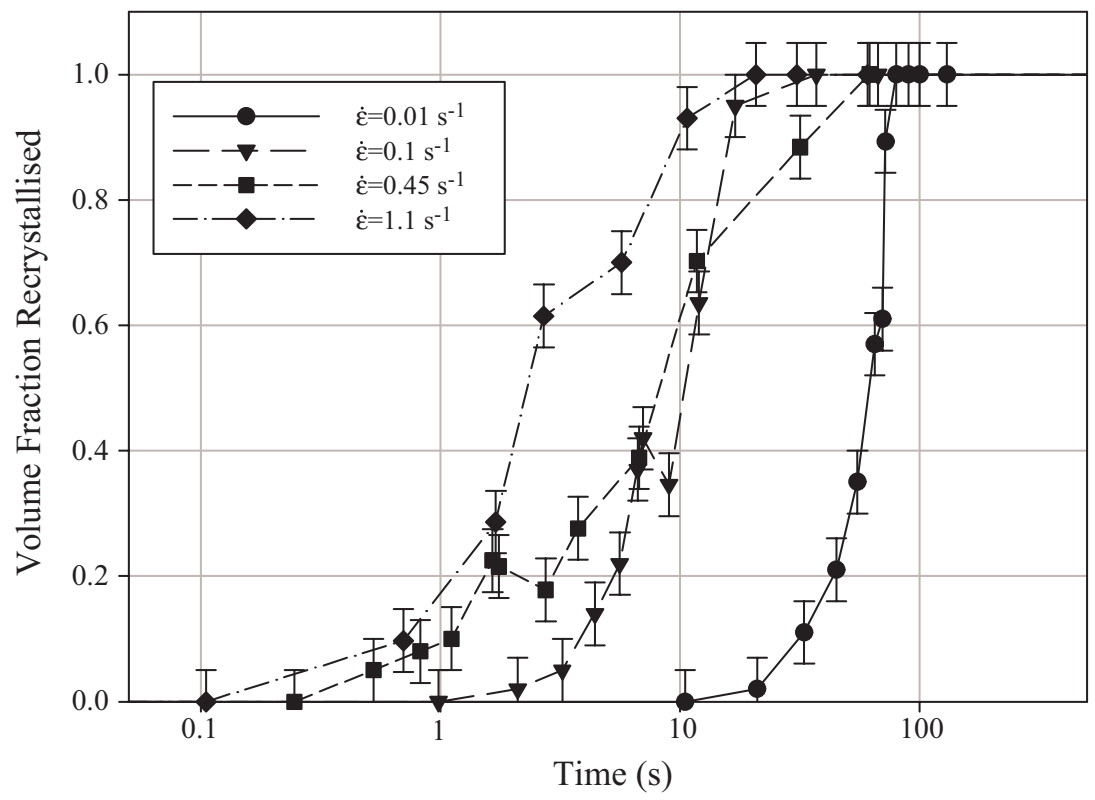

Figure 4: Combined graph showing the volume fraction dynamically and meta-dynamically recrystallised at $980^{\circ} \mathrm{C}$ as a function of time only

Figure 5 shows the combined volume fraction recrystallisation curves for tests carried out at $1040^{\circ} \mathrm{C}$. As with the tests carried out at $980^{\circ} \mathrm{C}$, a clear sigmoidal shaped curve is seen for the low strain rate tests during deformation, with complete dynamic recrystallisation occurring at a strain of approximately $0 \cdot 7$. For the remaining strain rates, the dynamic recrystallisation curves are almost identical until the final stages of deformation, at which point a higher volume recrystallised is observed for the lower strain rates. The rate of meta-dynamic recrystallisation for the different strain rates are similar, and complete recrystallisation is observed less then 10 seconds after the end of deformation for all but the $0 \cdot 46 \mathrm{~s}^{-1}$ strain rate tests, where more than $95 \%$ recrystallisation was observed after this time. 


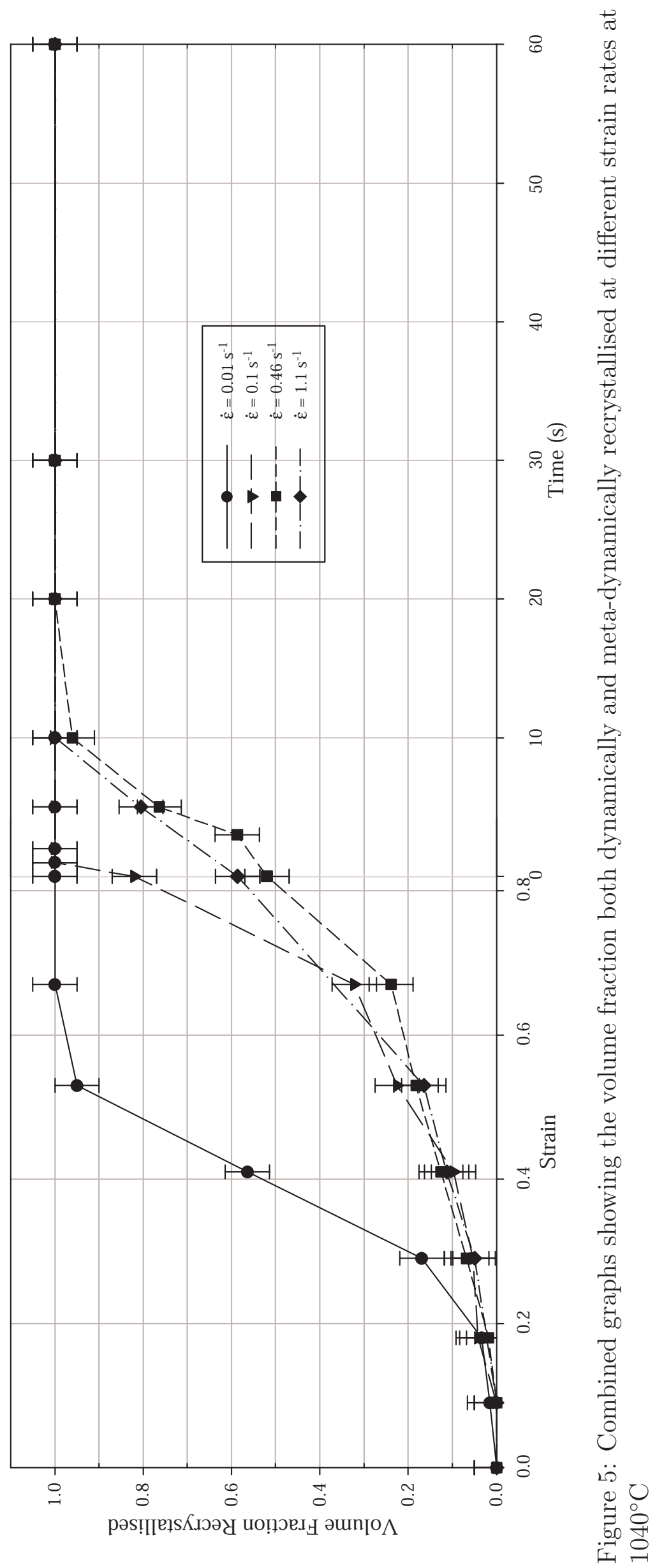


Although the dynamic recrystallisation curves in Figure 5 show the expected general trends (of increasing volume fraction recrystallised with increasing strain / time), it is possible that, at $1040^{\circ} \mathrm{C}$, the rate of recrystallisation is too rapid to be able to detect subtle differences between deformation at the higher strain rates using the methods employed here. It could also be inferred from these results, however, that for deformation at this high temperature, dynamic recrystallisation is dependant more on strain than on strain rate.

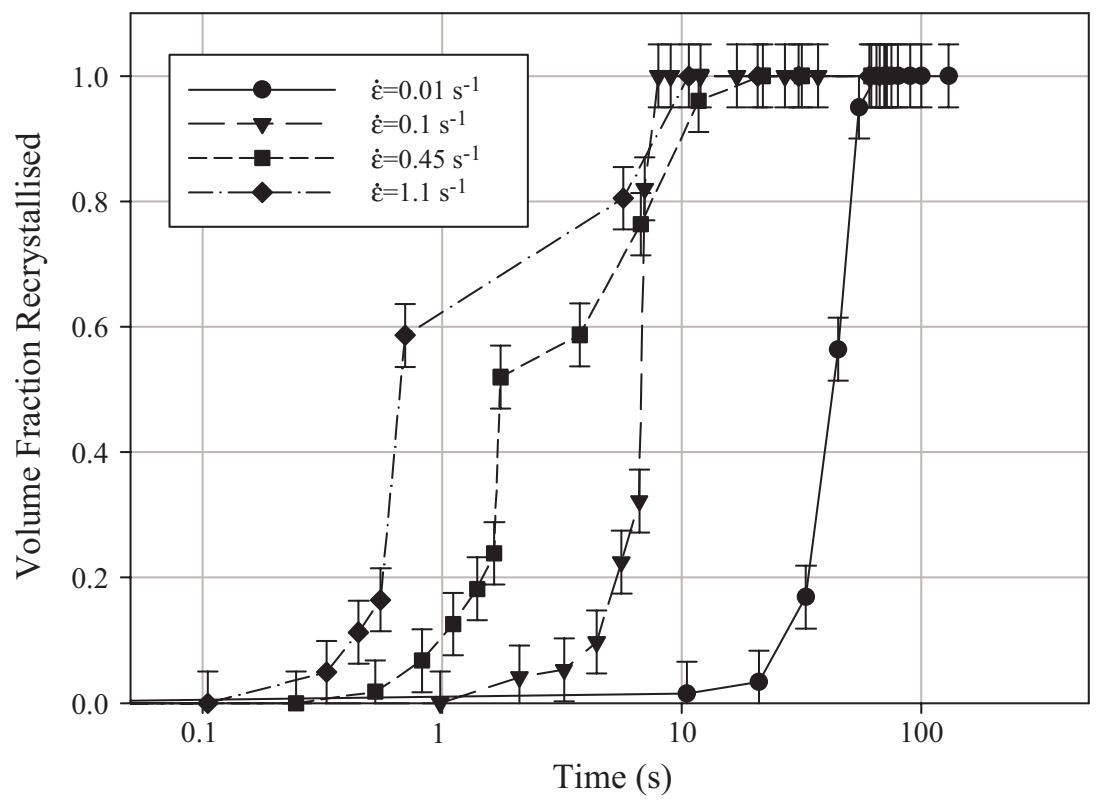

Figure 6: Combined graph showing the volume fraction dynamically and meta-dynamically recrystallised at $1040^{\circ} \mathrm{C}$ as a function of time only

To gain a full understanding of the recrystallisation kinetics, however, more information than just the volume fraction recrystallised should be analysed, and the number and size of grains must be investigated. Graphs showing the density of grains and, therefore, an indication of the nucleation rate during deformation at $980^{\circ} \mathrm{C}$ are shown in Figure 7 (a). Here, it can be seen that the nucleation rate during deformation at high strain rates is many times that at lower strain rates. For example during deformation at $980^{\circ} \mathrm{C}$ at a strain rate of $1.1 \mathrm{~s}^{-1}$, the average nucleation rate is $108 \times 10^{9} \mathrm{~m}^{-2} \mathrm{~s}^{-1}$. Deformation at a strain rate of $0.01 \mathrm{~s}^{-1}$, however, results in a nucleation rate of only $0 \cdot 3 \times 10^{9} \mathrm{~m}^{-2} \mathrm{~s}^{-1}$. This difference in nucleation rate can be attributed to a number of factors. Firstly, assuming that a similar number of dislocations are added to the system during deformation, regardless of strain rate [1]; the long time period over which the low strain rate tests were conducted will have allowed for a greater degree of recovery. This will have, in turn, lowered the dislocation density within the material and, therefore, will have decreased the driving force for nucleation of new grains and, hence, the nucleation frequency. Also a function of the extended time over which deformation occurs during the low strain rate tests, new recrystallised grains will be able to grow to a greater extent before the dislocation density within them reaches that of the surrounding matrix and causes them to stop growing. Also, as the temperature of the specimen during deformation at high strain rates is higher than during low strain rate deformation, nucleation, being at least partly a thermally activated process, will be accelerated during rapid deformation.

In all but the highest strain rate at $980^{\circ} \mathrm{C}$, the number of grains present in the system decreases dramatically after the completion of the deformation part of the test. This indicates that nucleation of recrystallised grains after deformation has finished is rare, and 
that an incubation period between the end of deformation and the onset of meta-dynamic recrystallisation does not exist (as was stated by Sun and Hawbolt [2]).

$\underline{\text { Influence of Temperature }}$

Figures 3 and 5 compare the volume recrystallised graphs for both different strain rates and temperatures. At the end of deformation (a strain of 0.82), the experiments carried out at $1040^{\circ} \mathrm{C}$ have resulted in a significantly higher volume fraction recrystallised than those experiments carried out at $980^{\circ} \mathrm{C}$ at the same strain rate. There is a distinct difference, however, between the degree the temperature affects dynamic recrystallisation curves for the extreme high and low strain rates $\left(0 \cdot 01 \mathrm{~s}^{-1}\right.$ and $\left.1.1 \mathrm{~s}^{-1}\right)$ compared to the intermediate strain rates $\left(0.1 \mathrm{~s}^{-1}\right.$ and $\left.0.46 \mathrm{~s}^{-1}\right)$. The curves for the intermediate strain rates show little or no difference in volume fraction recrystallised regardless of temperature until after a strain of $0 \cdot 7$. The strain rates either side of these, however, show a higher fraction recrystallised throughout deformation when carried out at a higher temperature.

\section{Influence of Strain}

Strain is the most influential factor altering the microstructure during hot-deformation. As can be seen graphically in Figures 3 and 5, as the strain increases, so does the fraction dynamically recrystallised. The trend is a result of two factors. Firstly, as strain increases, the dislocation density within the material increases, resulting in the nucleation of new recrystallised grains being energetically favourable. The effect can be seen clearly in Figure 7 (a) where the grain density during deformation at $980^{\circ} \mathrm{C}$ is plotted against strain for different strain rates. As the strain increases, the density of grains also increases, indicating ongoing nucleation during deformation. The second way in which strain effects the volume fraction dynamically recrystallised is by increasing the deformation time. Regardless of the strain rate, increasing the strain increases the duration of time over which deformation occurs. This results in not only extra time for more nuclei to form, but also more time for recrystallised nuclei to grow into the surrounding matrix, increasing the recrystallised volume fraction.

\section{Influence of Strain Rate}

It has already been shown that increasing the strain rate decreases the volume fraction dynamically recrystallised. Figure 8 shows the microstructures produced during deformation to a strain of 0.82 at $980^{\circ} \mathrm{C}$ at different strain rates. It is clear that not only is the volume fraction recrystallised lower for the higher strain rate experiments, but that the recrystallised grains are smaller after high strain rate deformation. This difference in grain size is due to the increased time that the grains have to grow in the low strain rate experiments, both due to the actual increased time of the experiment, but also due to the reduced rate of dislocation addition thus allowing the recrystallising grains to grow to a greater degree before they stop.

It would not be unreasonable to assume that once the critical strain for the onset of dynamic recrystallisation had been reached, the volume fraction recrystallised would simply be related only to the time elapsed from this point. Figure 9 has been plotted to test this hypothesis, and shows the dynamic recrystallisation curves plotted against time rather than strain. The volume fraction dynamically recrystallised curves have been shifted along the time axis such that the volume fraction recrystallised just before the critical strain is reached are aligned. These graphs prove that strain rate affects recrystallisation kinetics in a way more complicated than by just altering the time over which dynamic recrystallisation can 

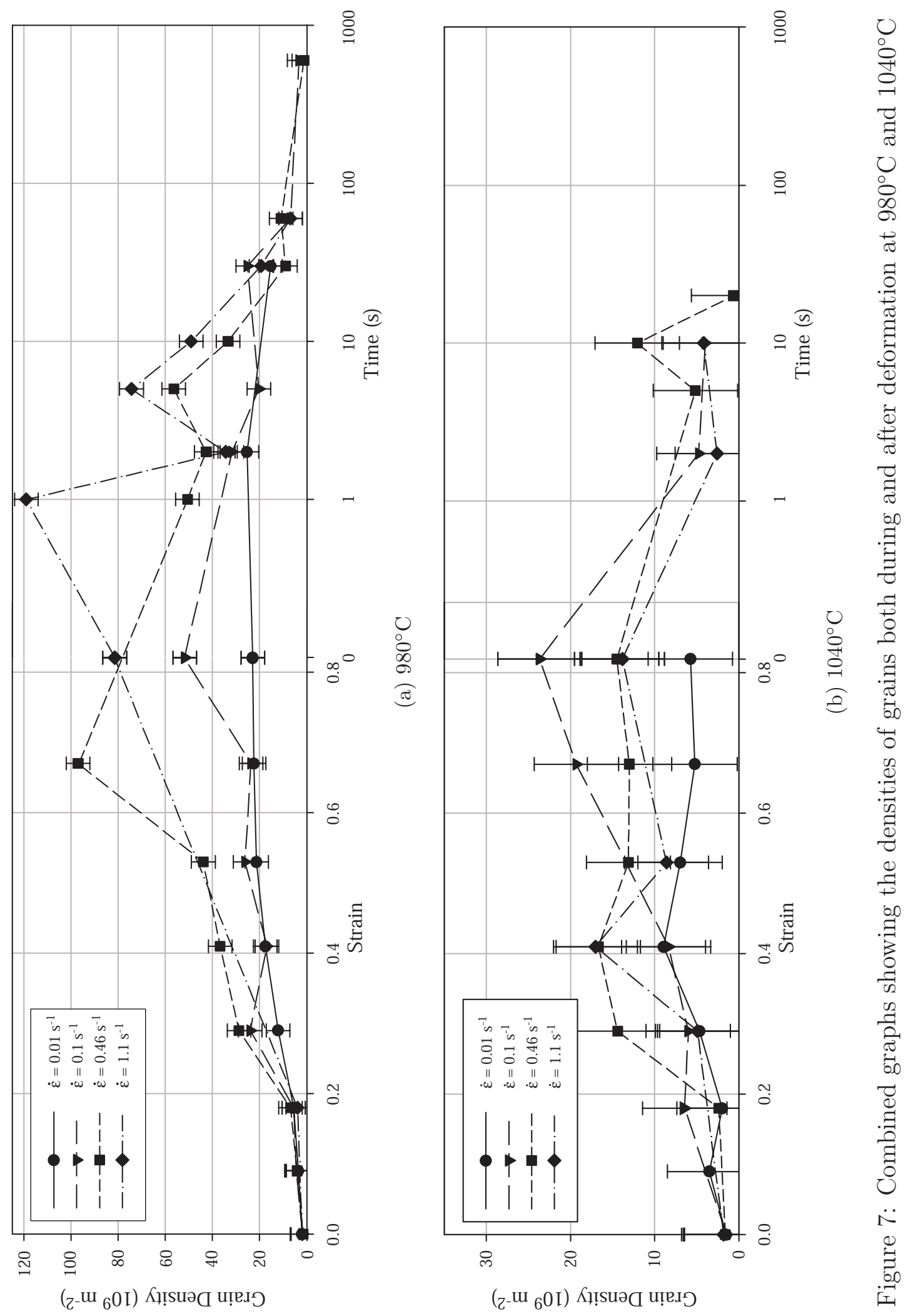


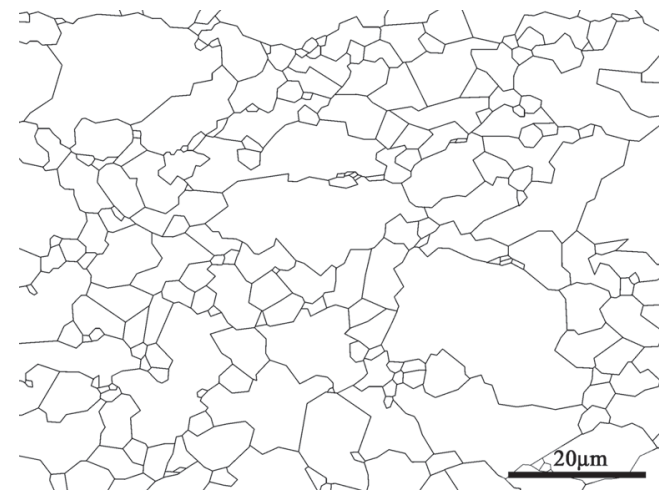

(a) $0 \cdot 01 \mathrm{~s}^{-1}$

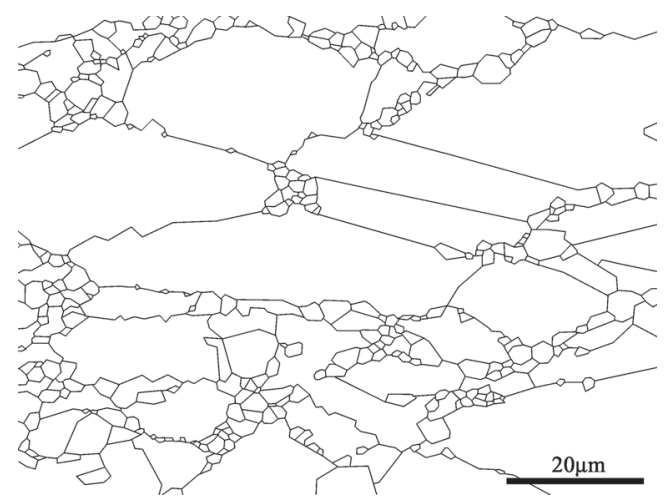

(c) $0.45 \mathrm{~s}^{-1}$

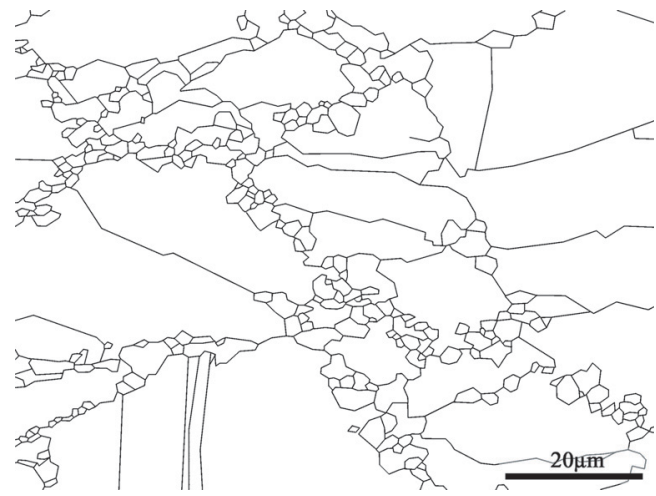

(b) $0 \cdot 1 \mathrm{~s}^{-1}$

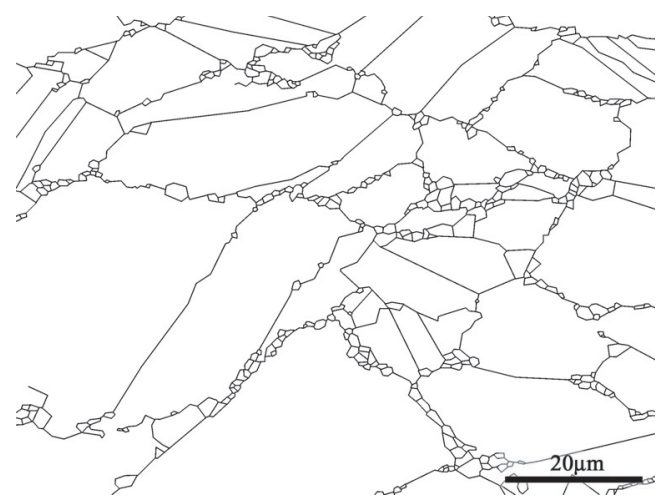

(d) $1.1 \mathrm{~s}^{-1}$

Figure 8: Outlines showing the microstructure after deformation to a strain of 0.82 at $980^{\circ} \mathrm{C}$ for different strain rates

occur. If this simple case was in fact true, the lines shown in Figure 9 would lie on top of one another.

The volume fraction recrystallised results presented here, shown at $980^{\circ} \mathrm{C}$ against strain in Figure 3, agree with Brand and coworkers [3] and Camus et al. [4] who have explained the increased rate in meta-dynamic recrystallisation after deformation at high strain rates as a result of adiabatic heating. The observation that a shorter time before the onset of meta-dynamic recrystallisation resulted from an increase in strain rate and an increase in strain made by Sun and Hawbolt [2] has not been validated in this work as post deformation hold periods were not subjected to samples deformed to strains other than $0 \cdot 82$, however, this observation would fit in both with the experimental results shown here, and the theory already discussed as an increase in strain rate or strain would increase the dislocation density within the material, increasing the probability of nucleation events occurring.

\section{Effect of Holding Time}

As previously discussed, the effect of increasing the holding time is that of increasing the volume fraction recrystallised. In addition to this, however, it is important to note that the nucleation of new grains during meta-dynamic recrystallisation is extremely rare. This would tend to indicate that dynamic recrystallisation is a process involving both the nucleation and growth of new grains, whereas meta-dynamic recrystallisation involves only the growth process. 


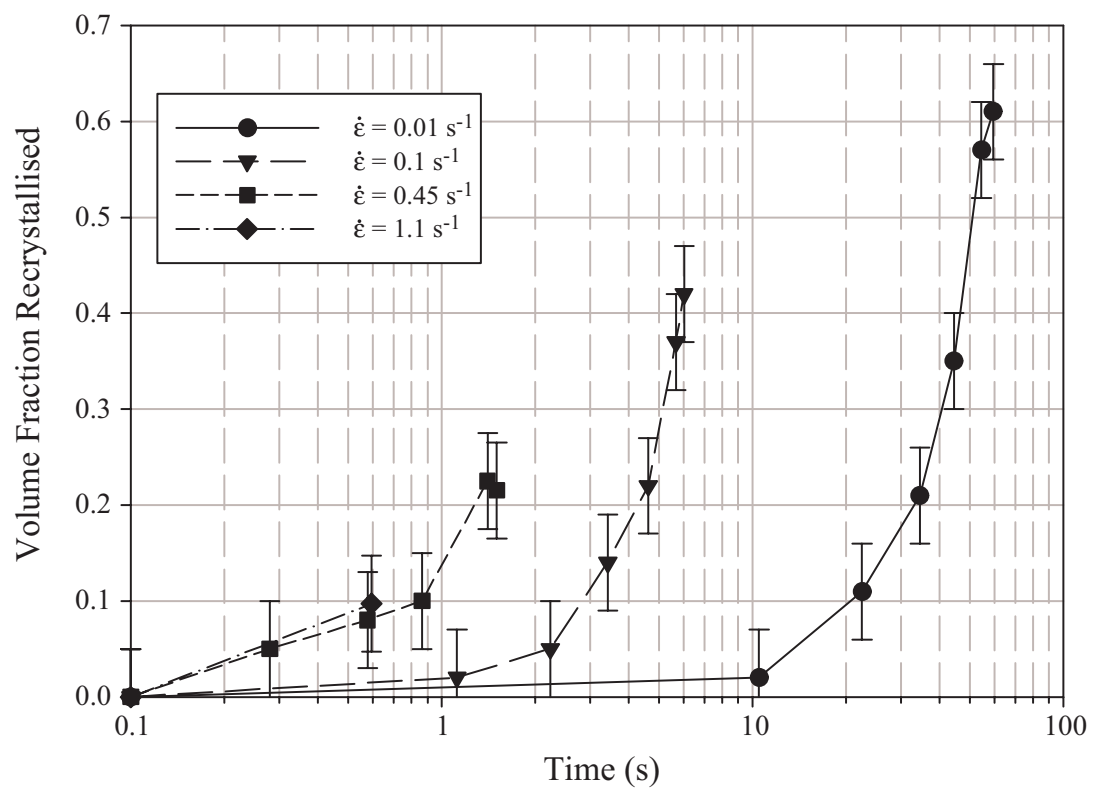

(a) $980^{\circ} \mathrm{C}$

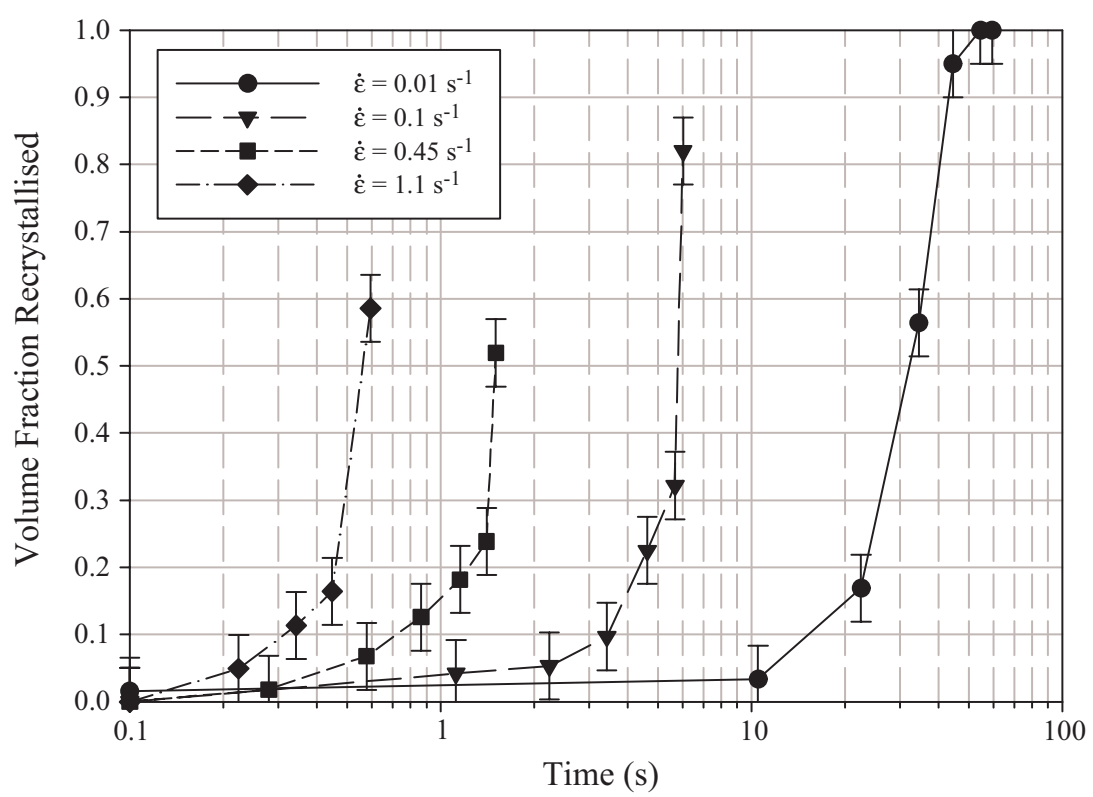

(b) $1040^{\circ} \mathrm{C}$

Figure 9: The effect of strain rate on volume dynamically recrystallised, plotted against time starting with the time at the critical strain for dynamic recrystallisation

\section{Conclusions}

As expected, the rate of dynamic recrystallisation was seen to increase with increasing temperature. For low strain rate tests, classical sigmoidal behaviour was observed as the strain was increased. Strain rate was seen to be inversely proportional to volume fraction recrystallised, explained primarily due to the reduction in deformation time. The nucleation rate of dynamically recrystallising grains was found to be much greater for deformation at higher strain rates, attributed to the higher dislocation density found in the material due to a lower degree of recovery, and to the increased grain boundary area on which to nucleate new grains. This extra grain boundary area is a result of the nucleation of new grains which do not grow 
by any discernable extent before the dislocation density within them is equal to that of the matrix.

When comparing the results from this investigation to those previously published, it is clear that there are distinct differences. Medeiros et al. [5], amongst others, for example, have published equations relating the meta-dynamically recrystallised grains size to strain rate and temperature only. It is clear to see from these results that the time between the end of the deformation period and the time of analysis has a large influence on the observed grain size. Also, it is unclear how equations from many of the studies reported in the literature describing the kinetics of meta-dynamic recrystallisation utilise strain rate as a variable. By definition, the strain rate during meta-dynamic recrystallisation is zero, and it is unclear if the average strain rate during deformation, or the strain rate during the final stage of deformation should be used in the equations.

From the experiments detailed here, however, it can be stated that it is futile to describe meta-dynamic recrystallisation without first investigating dynamic recrystallisation. This can be concluded as the meta-dynamic recrystallisation of IN 718 is purely the growth of the preexisting dynamically recrystallised grains, and does not involve the nucleation of new recrystallising nuclei.

\section{References}

[1] H. J. McQueen. The experimental roots of thermomechanical treatments for aluminium alloys. Journal of Metals, 32:17-26, February 1980.

[2] W. P. Sun and E. B. Hawbolt. Prediction of the onset of static recrystallization after hot deformation. ISIJ International, 35(7):908-913, 1995.

[3] A. J. Brand, K. Karhausen, and R. Kopp. Microstructural simulation of nickel base alloy inconel 718 in production of turbine discs. Materials Science and Technology, 12:963-969, November 1996.

[4] D. E. Camus, R. A. Jaramillo, J. A. Plyburn, and F. S. Suarez. Evolution of microstructure during hot rolling of inconel alloys 625 and 718. Superalloys 718, 625, 706 and Various Derivatives, pages 291-302, 1997.

[5] S. C. Medeiros, Y. V. R. K. Prasad, W. G. Frazier, and R. Srinivasan. Microstructural modeling of metadynamic recrystallization in hot working of IN 718 superalloy. Materials Science and Engineering A, 293:198-207, 2000. 